\title{
As FONTES ORAIS E SUA RELEVÂNCIA NOS ESTUDOS \\ LINGUÍSTICO-HISTORIOGRÁFICOS
}

(The relevance of oral sources en linguistic historiography)

\author{
Ricardo CAvaliere \\ (Universidade Federal Fluminense)
}

\begin{abstract}
Regarding historiographical sources, it is known that, in principle, the documentary sources are of greater suitability for the unveiling and interpreting the facts, given its presumption of trustworthiness as a bistorical document. Nevertheless, nowadays the relevance of the so-called informal sources, such as private letters, diaries, family notes and many others of this nature, is increasing substancially, as well as the oral sources, whose importance as historical document must be reassessed. This text treats especially the oral sources in the field of Linguistic Historiography, as well as its use in contemporary research projects dedicated to the study and analysis of the linguistic knowledge building in Brazil.
\end{abstract}

Key-words: linguistic historiography; canonical sources; oral sources; relevance.

Resumo: No que se refere às fontes historiográficas, sabe-se que, em princípio, as de natureza documental são de grande utilidade para esclarecimento e interpretação dos fatos, dada a presunção de confiabilidade de que desfrutam como documento histórico. Hoje, contudo, cresce significativamente a relevância das fontes informais, tais como as cartas, os diários, os bilhetes familiares e outras dessa natureza, assim como as fontes orais, cuja importância como documento histórico deve ser reavaliada. Este texto trata em especial da fontes historiográficas orais no campo da Historiografia da Linguística, bem como de sua utilização em projetos de pesquisa contemporâneos que se dedicam ao estudo e análise do percurso do saber linguístico no Brasil.

Palavras-chave: historiografia lingüística; fontes canônicas; fontes orais; relevância.

\section{INTRODUÇÃO}

Quando se cuida da distinção entre os domínios da História e da Historiografia, costuma-se afirmar que a primeira se ocupa dos fatos ocorridos no passado, enquanto a segunda se dedica ao estudo dos textos que os historiadores escrevem sobre os fatos passados. 
Muitas vezes, porém, esta distinção resulta numa indesejável imiscuição de conceitos, de tal sorte que os dois campos de investigação costumam ser designados indistintamente. Obras historiográficas, em termos mais acurados, não são simplesmente cronologias de fatos históricos (isto é, nomes, datas, lugares e ocorrências), senão juízos e interpretações sobre o passado que emergem da evidência histórica. Considerando que o mister historiográfico implica uma progressiva e renovada interpretação da História em sentido estrito, resulta admitir que, em órbita historiográfica, o passado está sempre em construção. É exatamente nessa dimensão que se pode compreender a conhecida afirmação do escritor norte-americano William Faulkner de que o passado não está morto, visto que a rigor não é passado ${ }^{1}$.

A Historiografia atesta este máxima. Embora os fatos do passado estejam alicerçados pela pluralidade de testemunhos e, portanto, integrem o que se costuma designar por "verdade histórica", seus elementos constitutivos, a natureza dos sujeitos envolvidos e até mesmo as delicadas relações de causalidade que lhes são inerentes passam pelos testemunhos não como a expressão monolítica da verdade, mas como um prisma de verdades. Numa dimensão historiográfica, a interpretação do historiógrafo impõe ao fato histórico o fado da constante mutação, porque, em termos definitivos, o que sabemos do passado não é uma história dos fatos, mas o que o discurso polifônico nos diz sobre eles. Eis por que o olhar historiográfico sobre o que se disse acerca do fato histórico conduz-nos ao que Le Goff rotulou como a "história da história" (Le Goff 1996: 12).

No tocante à Historiografia Linguística, tais asserções ganham relevo em face de sua relativa juventude no conjunto das disciplinas dedicadas à interpretação do saber científico. A própria definição de seu campo de atuação é ainda um dos maiores desafios para os que se dedicam à construção de seu aparato teórico. Valho-me aqui de uma delimitação do campo de atuação da Historiografia Linguística proposta por Pierre Swiggers (2010) que julgo bastante esclarecedora:

Linguistic historiography is the interdisciplinary study of the evolutionary course of linguistic knowledge; it encompasses the description and explanation, in terms of discipline-internal and discipline-external factors (the impact of which may be 'positive', i.e. stimulating, or 'negative', i.e. restraining or relegating), of how lin-

1. "The past is never dead. It's not even past (Falkner 1951). 
guistic knowledge ou, more generally, linguistic know-how was arrived at and has been implemented.

Como se percebe, a definição de Swiggers inscreve a Historiografia Linguística no conjunto das disciplinas que têm por objeto não os fatos, mas o discurso sobre os fatos, já que sua ocupação não está propriamente na referência ao saber linguístico constituído, senão no processo e nos procedimentos de sua construção. Decerto que, nesse mister, a práxis historiográfica impõe um amplo espectro de cooperação interdisciplinar, em que Linguística e História são eixos em torno dos quais circulam as contribuições da Filosofia, da Sociologia, da Antropologia, para aqui citarmos algumas poucas ciências de relevante papel no conjunto dessa interdisciplinaridade.

Esta é, por exemplo, a perspectiva com que Konrad Koerner, ao cuidar da metalinguagem no curso ou desenvolvimento da Linguística como ciência, alerta-nos de que as ideias linguísticas (como de resto as ideias lato sensu) não se desenvolvem divorciadas dos movimentos intelectuais de seu tempo em todas as áreas do fazer humanístico. Impõe-se, assim, uma árdua e exaustiva - até onde a disposição e capacidade humanas permitem - tarefa de contextualização das ideias linguísticas em seu tempo e seu cenário cultural, epistemológico, em sua episteme, para usarmos a terminologia de Michel Foucault (1966) ou sua atmosfera intelectual ${ }^{2}$, nas palavras de Konrad Koerner (1995).

É nesse sentido que, sintetizando exemplarmente, Pierre Swiggers situa a Historiografia Linguística como a disciplina que "oferece uma descrição e uma explicação da história contextualizada das ideias linguísticas" (Swiggers 2010: 2).

\section{A NATUREZa dAS FONTES historiográficAs}

Uma das tarefas de que se ocupa o historiógrafo da linguística diz respeito ao levantamento das fontes historiográficas. Sabe-se que, em princípio, as fontes documentais revestem-se de maior idoneidade para o descortinamento e interpretação dos fatos, dada sua presunção de idonei-

2. Climate of opinion, no original em inglês, expressão que se vem usando em português pela tradução literal "clima de opinião". 
dade como documento histórico. No âmbito da Historiografia Linguística, como ocorre em tantas outras áreas de pesquisa historiográfica, confere-se, via de regra, maior importância às denominadas fontes canônicas, ou seja, os textos escritos por linguistas cujo tema está vinculado ao estudo linguístico stricto sensu (gramáticas, dicionários, ensaios, resenhas críticas etc.), ao passo que se atribui menor relevância às chamadas fontes não canônicas, de caráter informal, tais como as cartas particulares, os diários, os bilhetes familiares e tantas outras congêneres. Entretanto, tais fontes, também consideradas marginais, não raro contribuem para esclarecer aspectos ideológicos de dado autor ou mesmo de dado grupo de cientistas irmanados no mesmo projeto de investigação, sobretudo em face das autoavaliações ou das críticas nelas presentes e ordinariamente ausentes nas fontes canônicas.

As fontes não canônicas ou marginais podem apresentar-se em modalidade escrita e oral. As de modalidade escrita são ordinariamente de caráter epistolar e não raro inscrevem a matéria linguística em outras questões de caráter difuso, fato que a princípio poderia entender-se como um óbice para seu aproveitamento como efetiva evidência historiográfica. No entanto, é justamente essa digressão por outras áreas de conhecimento, ou mesmo por temas absolutamente alheios ao interesse científico, que, por vezes, confere maior esclarecimento sobre fatos que insistem em manter-se sob as cobertas.

Um exemplo - dentre vários ainda não pesquisados - de fonte marginal no âmbito da linguística brasileira está na correspondência mantida por Manuel Said Ali (1861-1953) com Capistrano de Abreu (1853-1927) . Disponíveis em mais de uma publicação - sirvo-me aqui do terceiro volume de correspondência que integra a obra completa de Capistrano de Abreu publicada pela Editora Civilização Brasileira em parceria com o Ministério da Educação (Abreu, 1977) - as cartas de Said Ali ao dileto amigo revelam obrigatória presença dos temas linguísticos. Nelas, tomamos ciência de aspectos pouco estudados do trabalho cotidiano do filólogo fluminense, muitos deles relevantes para que se chegue a um completo e exato perfil de suas ideias linguísticas.

Cite-se, por exemplo, a referência que Said Ali traça acerca da obra de Kristoffer Nyrop (1858-1931), especificamente o volume de semântica da monumental Gramática histórica da língua francesa (Nyrop 1913), pub-

3. Um excelente estudo sobre a correspondência de Capistrano de Abreu encontra-se em Christino (2007). 
licada em seis volumes, obra em que o linguista dinamarquês cuida com especial relevo da mudança semântica em face da conexão ideológica que o falante mantém entre as palavras, fato que seria mais tarde conhecido como "campo semântico" nos estudos linguísticos do século XX. Ao que parece, Capistrano de Abreu emprestara a Said Ali os seis volumes da Gramática de Nyrop, solicitando-lhe, como usualmente fazia, um juízo crítico sobre a obra.

Embora não cite o linguista dinamarquês em seus estudos sobre alteração semântica (Ali 1930), evidencia-se que o bom proveito de que se serviu Said Ali com a leitura de Nyrop, visto que há extrema identidade conceptual nos dois trabalhos aqui citados. Por interessante notar, a referência expressa a Nyrop em Said Ali restrige-se ao campo da morfologia, em breve alusão aos conceitos de devivação e composição (Ali 1966[1908] 2).

Outra informação importante acerca da formação filológica de Said Ali que a leitura de sua correspondência ativa nos faculta diz respeito a sua firme convicção de que a principal fonte de pesquisa dos fatos linguísticos não estava nos teóricos, senão nos escritores clássicos. Em carta datada de 12 de julho de 1921, o mestre fluminense informa a Capistrano que a redação da Formação de palavras e sintaxe do português histórico (1923), texto que mais tarde seria reunido com a Lexeologia do Português Histórico (1921) na edição da Gramática histórica (1971 [1931]), passara "do movimento adágio (sic) para o de lento assai (Abreu, 1977:203). A causa é assim declinada:

Estou agarrado com a dificílima questão do emprego do conjuntivo. Ataco o problema pela parte analítica. Exemplos colecionados tenho-os em abundância, mas há deficiência para o esclarecimento de pontos de suma importância, e o único remédio é entrar novamente pela mata dos escritores e procurar e catar o que preste.

Já de outra missiva, esta datada de 9 de setembro de 1926 (Abreu 1977:204), vem-nos o seguinte passo:

No 2. ${ }^{\circ}$ vol. das Cartas de Vieira, encontro três exemplos valiosos da expressão adverbial por maior, sendo que da expressão de sentido oposto por menor, só possuo um exemplo. Da função e substanciação desta última não conheço caso, nem ainda em escritor mais moderno, como Herculano.

Essa afeição que Said Ali devotava ao texto literário como principal manancial dos usos linguísticos foi-me informalmente comprovada por 
Evanildo Bechara, que, na juventude, conviveu com Said Ali durante doze anos. Segundo Bechara, o velho mestre, ao introduzi-lo no mundo da pesquisa filológica, indicou-lhe como primeira leitura os autores clássicos, não os teóricos da Linguística, uma lição de que o espírito filológico se forma pelo acesso direto às fontes de uso linguístico, não às ideias preconcebidas sobre o funcionamento da língua.

Entretanto, não ficam por aqui as interessantes informações que a leitura da correspondência de Said Ali nos oferece sobre sua rotina de pesquisa. Há na carta datada de 8 de março de 1927 uma citação da Revista Glotta, periódico especializado em língua grega e latina, fundado por Paul Kretschmer e Franz Skutsch em 1909 e publicado pela Editora Vandenhoeck \& Ruprecht. Considerando que nenhum outro filólogo brasileiro cita diretamente os volumes da Glotta, cujos textos saíam em alemão e, em menor número, em inglês, reforça-se a tese de que o acesso às fontes germânicas constituía um dos privilégios de que desfrutava Said Ali no cenário filológico do período científico.

Na mesma carta de 8 de março de 1927, nosso filólogo traça referência às figuras de Alois Walde (1869-1924), Wallace Martin Lindsay (1858 -1937) e Édouard Sommer (1822-1866), ao longo de um comentário sobre a origem da palavra matrix. São nomes praticamente desconhecidos dos brasileiros nos verdores do século XX, sobretudo porque sua obra vinculava-se quase exclusivamente aos estudos clássicos. Alois Walde, filólogo austríaco de mediana presença no cenário do século XIX, ganhou prestígio pela publicação de um dicionário etimológico do latim (Walde 1906), por sinal obra em que Said Ali procurou as referências etimológicas de matrix. Lindsay, filólogo escocês, atuou como professor de língua latina na St. Andrews University. Embora tenha marcado presença bibliográfica com vários textos sobre o latim medieval, sua atuação não traz contributo excepcional para o estudo das línguas clássicas. Já Édouard Sommer é autor do Lexique français-latin, obra extraída do Dictionnaire français-latin (1860), de Louis-Marie Quicherat (1799-1884) e Amédée Daveluy. Surpreende que Said Ali tenha recorrido ao texto de Sommer, uma versão reduzida da obra que lhe deu origem, fato que só se pode atribuir à dificuldade de acesso à fonte bibliográfica principal.

A citação de tais nomes, enfim, revela este traço especial de Said Ali, qual seja o de manter-se, dentre os filólogos brasileiros do início do século 
passado, mais afinado com as fontes bibliográficas européias, mormente as concernentes aos estudos clássicos. Seguramente, não teríamos hoje ciência deste traço especial na formação acadêmica de Said Ali não fossem os documentos de sua correspondência ativa com Capistrano de Abreu, fato que revela, ainda que em pequena dimensão, a relevância de se recorrer às ditas fontes marginais no trabalho de levantamento e análise crítica dos fatos históricos.

A rigor, no caso específico de Manuel Said Ali, na hipótese de não contarmos com fontes documentais escritas, talvez pudéssemos hoje recolher as mesmas informações mediante recurso a outra fonte, igualmente idônea, na pessoa de um de seus mais diletos discípulos, o professor Evanildo Bechara, que, como já aqui assinalamos, conviveu com o mestre fluminense por mais de uma década, desfrutando inclusive do convívio mais íntimo em sua residência. Esta vertente que se abre com a possível utilização do depoimento pessoal de Bechara proporciona-nos a oportunidade de comentar uma outra face das denominadas fontes marginais no amplo campo da pesquisa linguístico-historiográfica.

\section{A RELEVÂNCIA DAS FONTES ORAIS}

A face a que me refiro diz respeito às fontes orais, cuja utilização tem sido objeto de expressiva controvérsia no corpo da pesquisa historiog ráfica, sobretudo quanto a sua idoneidade e credibilidade. A grande objeção que se opõe ao uso dessas fontes na construção do saber historiográfico diz respeito ao cunho excessivamente subjetivo das informações delas abstraídas, muitas vezes colidentes com informações outras de caráter documental. Neste sentido, surge uma questão preliminar que permeia a delimitação de critérios confiáveis para a utilização das fontes orais, de tal sorte que sua contribuição seja avaliada na justa medida e o fato histórico seja interpretado em bases científicas.

Considerando a crescente participação desse tipo de fonte historiográfica no conjunto dos meios utilizados para tecer juízo crítico, cumpre avaliar em que medida a denominada História oral pode (ou mais adequadamente „deve“) participar do conjunto de evidências que conduzem à formação de juízo crítico imparcial. Nesse sentido, convém citarmos aqui uma experiência referida por Etienne François (1988:10-11), que bem elucida a importância das fontes orais na construção do saber sobre o passado: 
Estudando já há vários anos, numa perspectiva de história social e de demografia histórica quantitativas, a evolução das estruturas familiares da Europa central do período moderno ao início do nosso século, Michael Mitterauer, titular da cadeira de história econômica e social da Universidade de Viena, ficou impressionado com o contraste ente a enorme importância, em todos os estados, da população que ele inclui na rubrica "trabalhadores diaristas, domésticos e criados" e o extremo laconismo, para não dizer mutismo, da documentação escrita no tocante a toda essa parte da antiga sociedade rural. [...] Com a ajuda de estudantes do seu seminário, ele organizou, para colher depoimentos, vários encontros com pessoas idosas que viviam em Viena mas eram oriundas do proletariado rural, nascidas e criadas no campo, no fim do século passado e no início deste. Ora, esses encontros logo deram origem a uma dinâmica inesperada e impetuosa, que levou historiadores e depoentes muito além dos objetivos iniciais. De fato, não só eles atraíram a atenção dos pesquisadores para aspectos da condição rural até então insuficientemente considerados (em particular o problema da ilegitimidade), mas sobretudo suscitaram entre as pessoas entrevistadas reações emocionais muito fortes, sempre que elas se viam confrontadas com aspectos sensíveis (e enterrados) de sua juventude (pobreza, privação, miséria, dependência, incerteza do futuro etc.), despertando-lhes assim a vontade de participar ativamente da pesquisa em curso - numa perspectiva emancipadora de recuperação de sua própria história reprimida e, portanto, de redescoberta de identidade - e levando os historiadores a se interrogarem sobre sua maneira de relacionar-se e comunicar-se com aqueles cuja história estão escrevendo.

O exemplo referido por François revela a um tempo dois aspectos cruciais atinentes ao uso de fontes orais: de um lado, desnuda-se a face oculta dos fatos, desenhada pelos depoimentos dos que os testemunharam sem a obrigatoriedade de fazer-lhes um relato oficial ou socialmente determinado, como ordinariamente ocorre nas fontes documentais escritas; de outro, evidencia-se a influência do interesse subjetivo no testemunho, de que constitui prova o clima emotivo e altamente participativo dos depoentes. Assim, a questão de base com que se defronta o historiógrafo situa-se nos limites de utilização das fontes orais como evidência histórica idônea, confiável, ou seja, apresenta-se-lhe o dilema de definir se o material que está à disposição serve para a construção de uma "história científica" ou uma "história militante", se seu conteúdo tem finalidade cognitiva ou propósito político.

No Brasil, por exemplo, para darmos aqui um toque doméstico a essa questão de base, muito se comenta sobre a pouca afeição que tinha Mattoso Camara (1904-1970) às questões sintáticas, já que, no conjunto de sua expressiva obra linguística e filológica - que inclui vasto repertório de 
livros didáticos, manuais teóricos, dicionários, estudos avulsos de temática vária - poucos são os trabalhos exclusivamente dedicados à sintaxe. A causa, infere-se, estaria na rígida formação teorética de Mattoso na seara do Estruturalismo europeu e norte-americano, cujas bases se assentavam mais nitidamente nos estudos fonológicos e morfológicos.

No entanto, algumas das fontes orais sobre a atividade acadêmica de Mattoso - refiro-me aqui, especificamente, ao testemunho de Carlos Eduardo Falcão Uchôa, colaborador de Mattoso Camara na Universidade do Brasil -, revelam que o interesse do autor dos Princípios de linguística geral (1942) não excluía a sintaxe, o que se comprova com sua intenção de traçar uma ampla e profunda descrição dos mecanismos de criação frasal no projeto de uma gramática descritiva da língua portuguesa ${ }^{4}$. Entretanto, os sintomas cada vez mais severos da doença que lhe arrebataria a vida, imiscuídos com um sentimento depressivo que o fazia repetidamente falar em aposentadoria e na proximidade dos 70 anos de idade, arrefeceram-lhe o ânimo para a conclusão do projeto. É pelo testemunho de Carlos Eduardo Falcão Uchôa que nos chega hoje a informação de que o próprio Mattoso tinha consciência de que não conseguiria chegar ao capítulo da sintaxe tendo em vista seu precário estado de saúde.

No conjunto das pesquisas linguístico-historiográficas contemporâneas, destaca-se, como instrumento produtor de fontes orais, o projeto Primeira Pessoa do Singular, que busca registrar em arquivos digitais o depoimento de linguistas que testemunharam o percurso dos estudos sobre a língua no Brasil bem como a presença e desenvolvimento desses estudos no meio acadêmico nacional. No plano brasileiro, portanto, o referido projeto pretende criar fontes orais primárias, já que pautadas em depoimentos de personagens partícipes dos fatos históricos.

Em sua gênese, entretanto, o projeto Primeira Pessoa do Singular, ao que consta, tinha objetivos mais amplos, já que atinentes à produção de fontes orais primárias e secundárias. Aparentemente, a ideia de escrever uma história informal da Linguística partiu de Willian Austin (1914-1971) em um dos encontros que mantinha regularmente com William Card (19061984), Virginia Mac David e Raven McDavid Jr. (1911-1984). Segundo esse último, Austin, em um dos encontros realizados no início de 1971, fez

4. O texto incompleto veio a lume postumamente sob o título Estrutura da língua portuguesa (1970). 
observar que muitos dos fatos que integravam a construção do pensamento linguístico norte-americano não estavam registrados em lugar algum, já que apenas armazenados na memória dos que deles participaram. Propôs, então, que se criasse um projeto que registrasse com metodologia científica a memória dos fatos atinentes à atividade do linguista como profissional acadêmico mediante depoimento pessoal dos envolvidos. A morte de Austin em setembro de 1971 não impediu que sua idéia original ganhasse adeptos nos círculos norte-americanos, de tal sorte que vários textos começaram a ser publicados nessa linha metodológica, que leva em conta as fontes orais que se materializam em cada linguista disposto a relatar suas experiências no campo profissional.

Em 1980, Boyd H. Davis e Raymond K. O'Cain organizam o volume First person singular: papers from the conference on an oral archive for the bistory of American linguistics (1980), uma coletânea de textos apresentados por linguistas norte-americanos, dentro da metodologia da História oral, em um encontro realizado nos dias 9 e 10 de março de 1979 Universidade da Carolina do Norte. Basicamente um conjunto de relatos autobiográficos - referidos pelos organizadores como "memória tribal" - a importância desses trabalhos para o estudo historiográfico da linguística ainda está por avaliar-se. A rigor, os textos de First person singular estão mais ligados à atividade profissional do linguista do que à Linguística propriamente dita. Trata-se de relatos que dão conta do desabrochar de uma vocação para os estudos linguísticos, ou mesmo de fatos fortuitos que levaram dada pessoa a enveredar pelo campo da investigação linguística.

Cerca de uma década depois, Konrad Koerner organiza o First person singular II (1991), em que se consolida a feição autobiográfica do projeto. A diferença está em que os textos são mais longos, preparados para uma publicação científica sem a preocupação com a extensão. Tal fato libera os autores para tecer comentários contextualizadores acerca de sua formação como linguistas, tais como a opinião familiar, o contato acadêmico com próceres da ciência linguística e a trajetória vulgarmente hesitante que cada um deles teve de cumprir entre as trilhas da Filologia e da Linguística. Por outro lado, essa fonte a rigor não pode ser classificada como fonte oral, já que os textos são escritos na mesma modalidade que levaria à produção de um ensaio comum.

No Brasil, a concepção do projeto Primeira pessoa do singular não tem esse perfil estritamente autobiográfico, já que se pauta na gravação de entrevistas com linguistas que tiveram relevante presença no percurso histórico 
da Linguística brasileira. Seu objetivo principal está na Historiografia da Linguística, não na vida pessoal dos linguistas, razão por que as entrevistas sempre procuram inscrever os depoimentos em fatos que tenham efetivo interesse para o desvendar das sendas percorridas pela ciência linguística entre nós. Atualmente, seguem em curso programas de pesquisa historiográfica nessa linha, desenvolvidos por mais de um núcleo de investigação, tais como o Centro de Documentação em Historiografia da Linguística (CEDOCH) da Universidade de São Paulo, cujo projeto A linguística no Brasil: estórias e histórias em primeira pessoa do singular é coordenado pela Professora Cristina Altman, e o Instituto de Pesquisas Linguísticas Sedes Sapientiae da PUC-SP (IP-PUC-SP), cujo grupo de pesquisa Historiografia da língua portuguesa é liderado pelas Professoras Neusa Bastos e Dieli Vesaro Palma.

O Primeira pessoa do singular visa, em princípio, a criar um corpus de pesquisa historiográfica dotado de arquivos eletrônicos textuais e icônicos catalogados. Nesse intuito, cuida-se, na entrevista, de obter dados biobibliográficos dos entrevistados a partir de sua própria voz, a par de traçar de seu perfil acadêmico e definir os temas de interesse que estavam no foco das preocupações acadêmicas de sua geração sua geração acadêmica. Assim, a autobiografia, que obviamente habita tais depoimentos, se imiscui com comentários de temática vária, cujos frutos são informações usualmente ausentes dos manuais de História da Linguística, cuja importância para a análise crítica dos fatos históricos revela-se verdadeiramente crucial.

Entretanto, lidar com o material recolhido no âmbito da História oral requer um cuidado redobrado. Decerto que seu objetivo não pode resumir-se à mera criação de arquivos, pois teríamos aqui uma riqueza de informações estagnada ou pobremente explorada. Ademais, os frutos da História oral mais se achegam, do ponto de vista metodológico, aos princípios historiográficos do que aos históricos, pois sua natureza é evidentemente de cunho axiológico, especulativo e analítico em plano multidisciplinar, tendo em vista que o intelectual depoente não raro transita em diversas áreas do saber humanístico.

\section{O TRATAMENTO ADEQUADO DAS FONTES ORAIS}

A experiência que já se vem obtendo há cerca de quatro décadas nos estudos historiográficos revela que os que se dedicam à criação de fontes 
orais podem situar-se em pelo menos quatro estereótipos (cf. Lozano 2005). O primeiro, já aqui referido, a que se pode denominar arquivista-documentalista, caracteriza-se pela organização de arquivos de áudio ou de documentos transcritos destinados à leitura de historiadores e historiógrafos. Um segundo tipo, a que se costuma denominar de difusor populista, confere ênfase aos fatos e versões que não constam nas fontes escritas canônicas. De orientação empirista, comete o mesmo equívoco de constituir amplos arquivos orais sem preocupação de análise, interpretação e mesmo depuração, não propriamente no sentido de editar as gravações, mas de encaminhar a entrevista no sentido de sempre conferir credibilidade às informações prestadas pelo depoente. Um terceiro tipo, a que se denomina reducionista interpreta a informação oral como uma ilustração dramatizada dos fatos que as fontes escritas tratam oficialmente, por vezes burocraticamente. Por fim, temos os analistas completos que "colhem, ordenam, sistematizam e criticam o processo de produção da fonte oral. Analisam, interpretam e situam historicamente as evidências orais. Complementam suas fontes orais com as outras fontes documentais tradicionais. Não se limitam a um único método e uma técnica, mas as completam e as tornam mais complexas" (Lozano 2005: 24).

No âmbito da Historiografia da Linguística, pode-se facilmente incorrer no erro de produzir fontes orais enviesadas pelo interesse axiológico. Quando se pensa em entrevistar alguém que possa contribuir para o esclarecimento maior de dado período da Linguística brasileira logo se selecionam nomes de escol, cujo sucesso acadêmico confira-lhes o que se pode denominar "autoridade científica". Trata-se de uma atitude parcialmente tautológica, pois frequentemente o que se obtém da voz desses nomes não vai muito além do que já se tinha registrado nas fontes canônicas.

Portanto, a postura mais adequada é a de democratizar a seleção dos depoentes, de tal sorte que entre eles estejam os linguistas de escol, os gramáticos escolares, os autores de apostilas, os professores de todos os graus de ensino, os gramáticos descritivistas e normativistas, enfim todos que viveram os fatos históricos. Teremos, pois, nos arquivos, a história dos vencedores e dos vencidos. Nesse aspecto, a História oral é efetivamente inovadora, pois dá voz aos silentes e excluídos da História calcada nas fontes canônicas. É uma História vista de todos os ângulos, de cunho eminentemente subjetivo, portanto sujeita a variáveis insuspeitas e perigosas na interpretação dos fatos. O que se quer é o enriquecimento das fontes 
disponíveis num processo dialético, a ponto de socializar a experiência, de conhecer e compreender a realidade histórica por meio de novas vertentes de reflexão sobre tais fatos.

Por outro lado, a fragilidade das fontes orais revela-se dramaticamente quando o historiógrafo se propõe a avaliá-las mediante critérios mais rígidos. Tome-se, por exemplo, a questão de sua credibilidade: o entrevistado pode ter uma falha de memória, pode criar involuntariamente uma trama fictícia ou mesmo jactar-se, fantasiar, omitir ou mesmo mentir. Sempre haverá algum "lucro" para a reunião de evidências, mesmo quando o pesquisador tenha certeza de que o depoente mentiu a respeito de dado fato histórico, já que caberia a ele, pesquisador, especular sobre os motivos que deram vezo à mentira. Saliente-se que, como nos alerta Gwyn Prins (1992), a par de uma tradição oral, que representa um testemunho transmitido de uma geração para a seguinte, existe também uma reminiscência pessoal, fruto específico das experiências de vida do informante. Portanto, ao deparar com uma inverdade declarada, o pesquisador não pode de imediato definir se se trata de uma falsa crença que o depoente recebeu de seus pares acadêmicos ou algo surgido na fantasia de sua mente.

Outras questões importantes haveriam de ser aqui tocadas no que diz respeito à criação de fontes orais em projetos como o Primeira pessoa do singular, dentre eles, por exemplo, a que diz respeito à figura do entrevistador. Deverá ser ele um linguista? Um historiador? Poderá formular perguntas do próprio alvedrio, ou deverá subordinar-se a quesitos predeterminados pelo grupo de pesquisa? São questões relevantes, se considerarmos que, como nos vem provando a Análise do Discurso, fatores extratextuais podem interferir na natureza semântica do texto, sobretudo num ambiente discursivo formal, tais como os que ordinariamente se erigem no ato da entrevista. Fica nestas linhas, ao menos, a crença de que não se pode atingir um resultado pleno em matéria linguístico-historiográfica sem que se inclua no rol das fontes disponíveis os relatos orais, sejam os de nomes que já alçaram ao reconhecimento histórico como protagonistas, sejam os de que se recolhem ainda à legião dos esquecidos e discriminados, visto que a verdade não mora em domicílio único nem tem endereço certo.

Recebido em julho de 2012 Aprovado em junho de 2013 E-mail: cavaliere@oi.com.br 


\section{REFERÊNCIAS BIBLIOGRÁFICAS}

Abreu, João Capistrano de. 1977. Correspondência de Capistrano de Abreu. 2 ed. Rio de Janeiro, Brasília: Civilização Brasileira, INL, v. 3.

AlI, Manuel Said. 1921. Lexeologia do português histórico. Rio de Janeiro: Melhoramentos.

. 1923. Formação de palavras e sintaxe do português histórico. Rio de Janeiro: Melhoramentos.

. 1930. Meios de expressão e alterações semânticas. Rio de Janeiro: Francisco Alves.

. 1966 [1908]. Dificuldades da língua portuguesa. 6 ed. Rio de Janeiro: Livraria Acadêmica.

. 1971[1931]. Gramática histórica. Rio de Janeiro/São Paulo: Acadêmica/Melhoramentos.

Camara, Joaquim Mattoso. 1941. Princípios de Lingüística Geral como fundamento para os estudos superiores da língua portuguesa. Rio de Janeiro: Briguiet.

. 1970. Estrutura da língua portuguesa. Petrópolis: Editora Vozes.

Christino, Beatriz Protti. A rede de Capistrano de Abreu (1853-1927): uma análise historiográfica do rã-txa bu-ni-ku-ì em face da Sul-americanística dos anos 1890-1929. São Paulo: Universidade de São Paulo, tese de doutoramento, 2007, mimeo.

Davis, Boyd H. \& O’CAIN, Raymond K. 1980. First person singular. Amsterdan: John Benjamins Publishing Company, Studies in the History of the Language Sciences, v. 21.

Faulkner, William. 1951. Requiem for a nun. New York, Random House.

Foucault, Michel. 1966. Les mots et les choses. Une archéologie des sciences bumaines. Paris: Gallimard.

François, Etienne. 1998. A Fecundidade da história oral. In: Amado, Janaína e Ferreira, Marieta de Moraes (coord.) Usos e abusos da história oral. Rio de Janeiro: Editora da Fundação Getúlio Vargas.

Koerner, E. F. Konrad. 1995. Metalanguage in linguistic historiography. In:_. Professing linguistic historiography. Amsterdam, Philadelphia, John Benjamins Publishing Co., p. 41.

- 1991. First person singular II: autobiographies by North American scholars in the language sciences. Amsterdan: John Benjamins Publishing Company, Studies in the History of the Language Sciences, v. 61. 
Le Goff, Jacques. 1996. História e memória. 4 ed. Campinas: Editora da Unicamp, trad. de Bernardo Leitão.

LozAno, Jorge Eduardo A. 1998. Prática e estilo de pesquisa na história oral contemporânea. In: Portelli, Alessandro; Ferreira, Marieta de Moraes e Amado, Janaína. Usos e abusos da história oral. Rio de Janeiro: Editora da Fundação Getúlio Vargas.

Nirop, Kristoffer. 1913. Grammarire historique de la langue française. Copenhague, Paris: Gyldendalske Boghandel-Picard.

Prins, Gwyn. 1992. Oral history. In: Burke, Peter (org.) New perspectives on historical writing. Pensylvania: Pennsylvania State University Press, p.172.

Quicherat, Louis-Marie et Daveluy, Amédée. 1860. Dictionnaire latinfrançais. Ed. revisé, corrigé et augmenté par Emile Chatelain. Paris: Hachette.

Silva Penna, Rejane. 2005. Fontes orais e historiografia: avanços e perspectivas. Porto Alegre: Edipucrs, Coleção Nova et Vetera 7.

Swiggers, Pierre. 2010. Eutomia. ano III, v. 2, dez. Disponível em http:// www.revistaeutomia.com.br/volumes/Ano3-Volume2/especial destaques/destaqueslinguistica/destaque_history_and_historiography_ of_linguistics.pdf. Consultado em 2 de janeiro de 2012.

W ALDE, Alois. 1906. Lateinisches etymologisches Wörterbuch. 1 Auflage. Winter, Heidelberg. 